\title{
Persuasive communication and the diminution of the salt intake in heart failure patients: a pilot study
}

\author{
Comunicação persuasiva e redução do consumo de sal em pessoas com insuficiência cardíaca: estudo-piloto
}

Comunicación persuasiva y reducción del consumo de sal en personas con insuficiencia cardíaca: estudio piloto

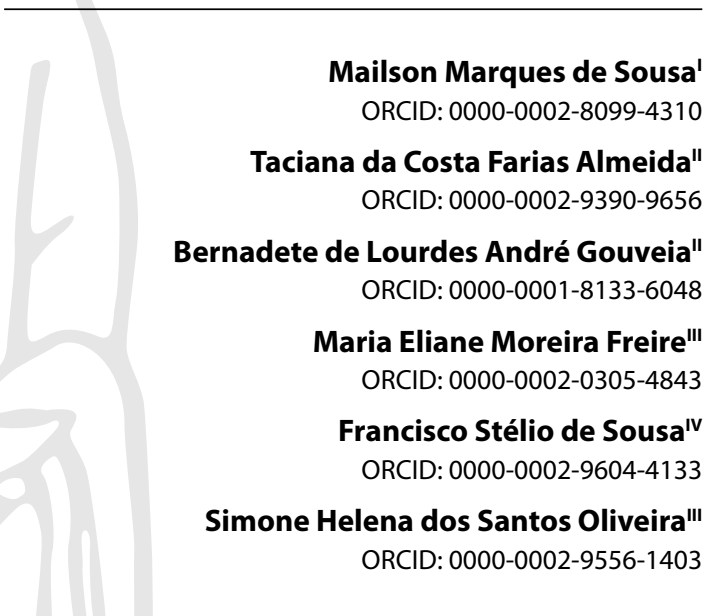

'Hospital Municipal Santa Isabel. João Pessoa, Paraíba, Brazil. "Universidade Federal de Campina Grande. Campina Grande, Paraíba, Brazil.

"'Universidade Federal da Paraíba. João Pessoa, Paraíba, Brazil. "Universidade Estadual da Paraíba. Campina Grande, Paraíba, Brazil.

How to cite this article: Sousa MM, Almeida TFC, Gouveia BLA, Freire MEM, Sousa FS, Oliveira SHS. Persuasive communication and the diminution of the salt intake in heart failure patients: a pilot study. Rev Bras Enferm. 2021;74(2):e20200715. https://doi.org/10.1590/0034-7167-2020-0715

Corresponding author:

Mailson Marques de Sousa

E-mail:mailson_ms@hotmail.com

EDITOR IN CHIEF: Dulce Barbosa ASSOCIATE EDITOR: Marcia Magro

Submission: $06-26-2020$

Aprovação: 12-21-2020

\begin{abstract}
Objectives: to evaluate the effect of persuasive communication in the modulation of the behavioral intention of reducing the consumption of salt in heart failure patients. Methods: pilot quasi-experimental study with one group, before and after the application of audiovisual persuasive communication, as guided by the Theory of Planned Behavior. This study used a form built and validated to measure behavioral variables (Beliefs, Attitude, Subjective Norm, and Perceived Behavioral Control). Wilcoxon's test and Spearman's correlation were applied. Results: 82 heart failure patients who were being monitored in outpatient clinics participated. The medians of the behavioral variables increased significantly after the exposition to persuasive communication, showing a high level of intention to execute the behavior. Conclusions: persuasive communication positively contributed to influence the behavioral intention of reducing the consumption of salt in people with cardiac insufficiency. Descriptors: Persuasive Communication; Heart Failure; Sodium-Restricted; Video-Audio Media; Intention.
\end{abstract}

\section{RESUMO}

Objetivos: avaliar o efeito de uma comunicação persuasiva na modulação da intenção comportamental de reduzir o consumo de sal em pessoas com insuficiência cardíaca. Métodos: estudo-piloto, quase-experimental, com grupo único, antes e depois de aplicação de uma comunicação persuasiva no formato audiovisual, norteado pela Theory of Planned Behavior. Utilizou-se formulário construído e validado para mensurar as variáveis comportamentais (Crenças, Atitude, Norma Subjetiva e Controle Comportamental Percebido). Aplicaram-se o teste de Wilcoxon e correlação de Spearman. Resultados: participaram 82 pessoas com insuficiência cardíaca em seguimento ambulatorial. As medianas das variáveis comportamentais aumentaram significativamente após a exposição à comunicação persuasiva, revelando alta intenção para executar o comportamento. Conclusões: a comunicação persuasiva contribuiu positivamente para influenciar a intenção comportamental de reduzir o consumo de sal em pessoas com insuficiência cardíaca.

Descritores: Comunicação Persuasiva; Insuficiência Cardíaca; Dieta Hipossódica; Mídia Audiovisual; Intenção.

\section{RESUMEN}

Objetivos: evaluar el efecto de una comunicación persuasiva en la modulación de la intención conductual de reducir el consumo de sal en personas con insuficiencia cardíaca. Métodos: estudio piloto, casi-experimental, con grupo único, antes y después de aplicación de una comunicación persuasiva en el formato audiovisual, basado en la Theory of Planned Behavior. Se utilizó formulario construido y validado para mensurar las variables comportamentales (Creencias, Actitud, Norma Subjetiva y Control de Conducta Percibido). Se aplicaron el test de Wilcoxon y correlación de Spearman. Resultados: participaron 82 personas con insuficiencia cardíaca en Clínica de atención sin turno previo. Las medianas de las variables comportamentales aumentaron significativamente después de la exposición a la comunicación persuasiva, revelando alta intención para ejecutar el comportamiento. Conclusiones: la comunicación persuasiva contribuyó positivamente para influenciar la intención conductual de reducir el consumo de sal en personas con insuficiencia cardíaca.

Descriptores: Comunicación Persuasiva; Insuficiencia Cardíaca; Dieta Hiposódica; Mediática Audiovisual; Intención. 


\section{INTRODUCTION}

Reducing the amount of salt in the diet is a non-pharmacological recommendation for people with heart failure (HF), aiming to diminish pulmonary congestion cases and to maintain clinical stability ${ }^{(1)}$. Studies point out that the non-adherence to the recommendations of a low-sodium diet explains from $22 \%$ to $69 \%$ of the rates of worsening of HF symptoms, leading to emergency hospitalizations associated to negative clinical outcomes ${ }^{(2-3)}$. However, scientific evidences about the ideal restriction in a low-sodium diet remain inconclusive, and new investigations on the theme are necessary $y^{(4-5)}$.

In spite of that fact, daily sodium intakes are recommended to be lower than 3 grams, or lower than 7 grams of sodium chloride (kitchen salt). This recommendation must consider clinical conditions, the progression of disease, and the pharmacological therapy in effect ${ }^{(6)}$. The Sociedade Brasileira de Cardiologia (Brazilian Society of Cardiology) and the American College of Cardiology encourage health professionals to educate those $\mathrm{HF}$ to reduce the consumption of salt in their $\operatorname{diet}^{(7-8)}$.

In the perspective of influencing behaviors that promote or protect health, studies have been conducted based on theoretical models whose target is understanding the motivation of the individual to execute them. In this research, the Theory of Planned Behavior - TPB - was chosen, since it is largely used to describe, explain, and predict human behavior under nonvolitional control, meaning that, in some situations, peoples depend on factors such as opportunity and necessary resources (time, money, aptitudes, cooperation from third parties) to behave in a certain way ${ }^{(9)}$.

According to the TPB, the intention is considered to precede immediately the behavior, and it is determined by three variables: Attitude, Subjective Norm, and Perceived Behavioral Control. The Attitude (At) is formed by Behavioral Beliefs (BBs), which are related to how favorable the subject is with regard to behaving or not in a certain way, and to evaluations of positive and negative consequences of the behavior. The Subjective Norm (SN) is related to the social influence, that is, to the perceived social pressure made up by Normative Beliefs (NBs) that are reflected in the perception of the individual about the opinions of their social referents about behaving a certain way or not, as well as to the individual motivation to agree with the social references. The Perceived Behavioral Control (PBC) is constituted by Control Beliefs (CBs), which consist in the perception of the individual with regard to their capacity of behaving or not in a certain way, as well as in the presence of factors that can make it more difficult to do $\mathrm{so}^{(9)}$.

According to the TPB, interventions that seek to change/ strengthen behaviors must be targeted at behavioral, normative, or control beliefs, which are the bases of attitudes, subjective norms, and perceived behavioral control. It is believed that these changes can influence even further the intention in the direction of the desire behavior ${ }^{(9-10)}$.

In this context, it becomes relevant to propose studies that evaluate human behavior to develop strategies of health intervention that can be effectively used in clinical practice. Persuasive communication, therefore, stands out as an intervention strategy to influence individual beliefs, norms, and attitudes that support a certain behavior ${ }^{(10)}$.

In the international setting, there have been studies that employed verbal instructions as a tool to persuade people with HF to follow a low-sodium diet ${ }^{(11-12)}$. In the Brazilian context, as this study was developed, no researches were found about the use of persuasive communication related to the adherence to a low-sodium/low-salt intake in this population.

Considering this context, for the use about the use of new technologies as adjuvant tools to conventional care strategies, this study seeks, through the use of audiovisual persuasive communication, contribute to increase the intention of people with $\mathrm{HF}$ to reduce the amount of salt in their diet, consequently diminishing clinical decompensation, hospital costs, and morbidity and mortality indexes ${ }^{(10,13)}$.

Furthermore, the incorporation of this strategy in nursing clinical practices, as a light-hard, low-cost, and easy to execute technology, has the potential to be successful in strengthening the interventions prescribed about the management of self-help actions directed at people with HF. Another justification is the fact that the theme of salt reduction is in the agenda of priorities of both the World Health Organization and of the Brazilian Ministry of Health, to control chronic noncommunicable diseases - especially cardiovascular problems ${ }^{(13)}$.

\section{OBJECTIVES}

To evaluate the effect of persuasive communication in the modulation of the behavioral intention of reducing the consumption of salt in heart failure patients.

\section{METHODS}

\section{Ethical aspects}

This research complied with all ethical prescriptions from Resolution n. 466/2012, on researches with human beings, and was approved by the Research Ethics Committee of the Lauro Wanderley Teaching Hospital. All participants signed the Free and Informed Consent Form (FICF) as formal recognition of their participation.

\section{Design and place of study}

This is a pilot, quasi-experimental study, with a single group and a quantitative approach. Data is part of a doctoral thesis entitled "Persuasive communication to motivate the intention of reducing salt consumption in individuals with heart failure"(13). The research was developed in two public hospitals associated to the Single Health System of the city of João Pessoa, PB, Brazil, in the cardiology outpatient clinics. Both hospitals are considered to be specialized centers for the assistance, teaching, and research in patients with cardiopathies.

Pilot studies aim to test strategies for interventions, sampling, recruiting participants, intervention protocols, data collection and analyses. This type of study is necessary before a larger clinical essay is carried out, to analyze and confirm the need for an intervention ${ }^{(14)}$. 


\section{Population, sample, criteria of inclusion and exclusion}

The target population of the study was made up by people with HF being monitored in the outpatient clinics of the institutions selected. Since this is a pilot study, there is no ideal formula to determine the sample size ${ }^{(15)}$, which was done in this work through the sequential inclusion of all eligible participants in the period of data collection, that is, from October 2018 to March 2019. As a result, 82 people with HF were invited.

All participants were selected according to the following inclusion criteria: people with a HF diagnostic confirmed in their medical records, 18 years old or older, from both sexes, regardless of etiology, with the HF categorized from I-III in the functional classes of the New York Heart Association (NYHA) ${ }^{(6)}$ and with a left ventricular ejection fraction (LVEF) $\leq 55 \%$, as described by the report from a transthoracic echocardiogram in the last three months, being monitored in the outpatient clinic.

Were excluded: people in their first consultation, since these could still be unaware of the measures of non-pharmacological management for the control of the HF; and people with hearing and/or visual impairments described in their medical records that could prevent them from hearing the persuasive communication, since it was presented in an audiovisual form.

\section{Study protocol}

Data collection took place through an individual interview, carried out by the main researcher, lasting for a mean of 42 minutes, in an isolated environment, in two stages, using two research instruments. In the first stage, a form was applied to characterize the sample the sample. It was the same used in a previous study ${ }^{(16)}$, which had been developed with people with $\mathrm{HF}$, and contained the following variables: age, sex, skin color, marital status, years of formal education, employment status, family income, HF etiology, functional class according to the NYHA criteria ${ }^{(7)}$, LVEF, comorbidities associated to the HF, and drug therapy in effect.

Then, a questionnaire was applied to measure the determining factors of the behavioral intention. It was built according to the theoretical precepts of the $\mathrm{TPB}^{(9,17)}$, and submitted to content and semantic validation ${ }^{(13)}$. The projected questionnaire is focused on the behavior of interest: reducing the consumption of salt in the diet for the next 30 days. The items were selected after the salient beliefs regarding the target behavior were surveyed, process which involved 26 people with HF being monitored in an outpatient clinic ${ }^{(16)}$. For data collection, it was found pertinent to adopt the typology "form", aiming to include people with a low educational level, characteristic that was often present in the investigation settings. Furthermore, the term "salt" was chosen, since it is easily understood by the population in addition to being the main source of sodium in the preparation of the diet ${ }^{(13)}$.

The instrument to measure the determinants of behavioral intention contains 30 items, separated in the following variables: Attitude (3 items), Behavioral Beliefs and assessment of consequences (8 items), Subjective Norm (1 item), Normative Beliefs, and motivation to agree with the referent ( 6 items), Perceived
Behavioral Control (2 items), Control Beliefs and Control Power (8 items), and Behavioral Intent ( 2 items). The response options are in a Likert scale that varies from 1 to 5, with bipolar semantic differential adjectives (unpleasant-pleasant, bad-good, uselessuseful, improbable-probable, disagree-agree) ${ }^{(13)}$.

The scores are calculated by constructs and evaluated separately. For direct measures (Attitude, Subjective Norm, and Perceived Behavioral Control), the score is calculated using the mean of the items; for indirect measures, the product of beliefs that the theory proposes was considered. It was calculated as follows: Behavioral Beliefs scores varied from 4 to 100 (strength of the behavioral belief $x$ evaluation of consequences); for Normative Behaviors, it varied from 3 to 75 (strength of the normative belief $x$ motivation to agree with the reference), and Control Beliefs varied from 4 to 100 (strength of the control belief $x$ control power). Therefore, the higher the score, the more favorable the person will be to the behavior ${ }^{(13)}$.

Regarding the reliability of the questionnaire, which was evaluated by Cronbach's Alpha before the persuasive exposition, the results were: $a=0.70$ for the Attitude construct; $a=0.81$ for the Subjective Norm; $a=0.72$ for the Perceived Behavioral Control; and $a=0.78$ for the general scale.

The persuasive communication, which was the intervention applied in this study, was elaborated earlier, considering behavioral, normative, and control beliefs of a representative sample of the research subject ${ }^{(16)}$. The production of the audiovisual media counted on the aid of a digital media professional, and its content was validated by professionals from the health field (two cardiologists, five nurses, and one nutritionist) who specialize in the care of people with HF, and by three professionals from the field of communications (two professors and one digital media professional) ${ }^{(13)}$.

The persuasive communication has language that is easy to understand, with images and animations to make understanding easier. It presents information about the concept of HF, the epidemiological data of the disease, its main signals and symptoms, persuasion about the advantages of reducing the consumption of salt, and the consequences of its excessive intake. It also talks about the importance of social references as support agents to follow a low-salt diet, measures that can make it easier to reduce salt, guidance to replace salt, and motivational messages to adopt the this behavior and capacity to follow a low-salt diet ${ }^{(13)}$. The final version lasts for 3 minutes and 46 seconds and is available at YouTube, in the channel Laboratório Tecnologias de Cuidado em Saúde (Laboratory Technologies of Health Care), from the teaching institution that houses the project. It is available at the address: https://youtu.be/GNqfSrgdX4l.

Before the persuasive communication was presented, the researched applied the instruments and filled them in according to the answers of the participants. After the information was collected, the intervention was presented to them, that is, the persuasive communication, which was reproduced in an $\mathrm{iPad}^{\circledR}$, using headphones. Immediately after the video was presented, the form was reapplied.

The choice to promptly apply the instrument again, after the persuasive communication was presented, was made to evaluate its immediate influence on the behavioral intention and the 
determinants with regard to diminishing salt consumption; as a result, sensible differences in behavior were not prioritized in the assessment, since these could not be assessed in such a small period of time. Furthermore, potential sample losses were pondered, considering the variability in the return to the consultations in the clinical cardiology services, as well as the need to observe the viability and acceptability of the intervention strategy for future applications ${ }^{(13)}$.

\section{Analysis of results and statistics}

Data analyzed using descriptive and inferential statistics, according to the recommendations of the Statistical Analyses and Methods in the Published Literature - SAMPL ${ }^{(18)}$. The categorical variables were described according to the calculation of absolute (n) and relative (\%) frequencies. For the continuous variables, the mean, standard deviation (SD), median, and interquartile range were calculated.

The normality of data was evaluated using the AndersonDarling test; since the distribution of the sample was found not to be normal, non-parametric tests were used. The scores of the direct measures (Attitude, Subjective Norms, and Perceived Behavioral Control) of TPB behavioral variables are presented by the medians of the data.

To analyze the indirect measures, the median of the product of the variables was considered. It was calculated as follows: behavioral beliefs $x$ consequence evaluation; normative belief $x$ motivation to agree; control belief $x$ control power - in accordance to the prescriptions of the $\operatorname{TPB}^{(9,13)}$. The non-parametric Wilcoxon test was used for paired data, to verify the difference in the results of the TPB constructs before and after the persuasive communication was shown.

Spearman's correlation was used to check the strength and meaning of relations between attitude, normative, and control components, with the depending variable (behavioral intention) before and after the exposure to the persuasive communication. The interpretation of correlation coefficients considered the following parameters: values below 0.30 were of weak magnitude; those from 0.30 to 0.50 were of moderate magnitude; and those above 0.50 were found to be of strong magnitude $^{(19)}$. The significance level adopted for the variables studied was $p<0.05$. All analysis were carried out using the statistical software R.

\section{RESULTS}

82 people with HF participated. The sociodemographic and clinical characteristics of the participants are presented on table 1 .

Table 2 shows the scores obtained from the behavioral TPB variables before and after the persuasive communication was applied. It can be found that the values increased in all TPB variables (direct and indirect measures), with a statistically significant difference $(p<0.05)$.

Table 3 shows Spearman's correlations between independent variables (direct and indirect measures) before and after the presentation to the persuasive communication, with the depending variable (behavioral intent). Earlier, significant positive correlations of weak and moderate magnitude were found for all independent variables and behavioral intent, except for the Perceived Behavioral Control. It can be noticed that, after the presentation, Normative Beliefs had a stronger correlation force with the Behavioral Intent (rho $=0,34 ; p<0,01)$.

Table 1 - Sociodemographic and clinical characteristics, João Pessoa, Paraíba, Brazil, 2019

\begin{tabular}{|c|c|}
\hline Variables & n (\%) \\
\hline Age $\left(\right.$ mean $\left.\pm S D^{*}\right)$ & $58.17 \pm 12.14$ \\
\hline Sex & \\
\hline Female & $48(58.5)$ \\
\hline $\begin{array}{l}\text { Self-declared skin color } \\
\text { Not white }\end{array}$ & $51(62.2)$ \\
\hline $\begin{array}{l}\text { Family arrangement } \\
\text { Lives with partner }\end{array}$ & $60(73.2)$ \\
\hline Years of study (mean \pm SD) & $4.88 \pm 4.27$ \\
\hline $\begin{array}{l}\text { Employment status } \\
\text { Inactive }\end{array}$ & $66(80.5)$ \\
\hline $\begin{array}{l}\text { Family income } \\
\quad<1 \mathrm{MW}^{+} \\
1 \text { to } 2 \mathrm{MWs}\end{array}$ & $\begin{array}{c}04(4.9) \\
74(90.2)\end{array}$ \\
\hline $\begin{array}{l}\text { Etiology } \\
\text { Ischemic } \\
\text { Non-ischemic }\end{array}$ & $\begin{array}{l}27(32.9) \\
55(67.1)\end{array}$ \\
\hline $\mathrm{LVEF} \pm($ mean $\pm \mathrm{SD})$ & $45.23 \pm 18.00$ \\
\hline $\begin{array}{l}\text { Functional class } \\
\text { NYHA§ I } \\
\text { NYHA II } \\
\text { NYHA III }\end{array}$ & $\begin{array}{c}32(39) \\
40(48.8) \\
10(12.2)\end{array}$ \\
\hline $\begin{array}{l}\text { Comorbidities associated to the HF } \\
\text { Systemic arterial hypertension } \\
\text { Diabetes mellitus }\end{array}$ & $\begin{array}{c}51(50) \\
24(23.5)\end{array}$ \\
\hline $\begin{array}{l}\text { Drug therapy } \\
\text { Diuretic } \\
\text { Beta blockers }\end{array}$ & $\begin{array}{l}51(38.1) \\
47(35.1)\end{array}$ \\
\hline
\end{tabular}

Table 2 - Comparison of the medians of the behavioral variables before and after the persuasive communication, João Pessoa, Paraíba, Brazil, 2019

\begin{tabular}{|c|c|c|c|c|}
\hline Variables & $\begin{array}{l}\text { Possible } \\
\text { variation }\end{array}$ & Before* & After* & $p$ value \\
\hline Attitude (At) & $1-5$ & $3.70(3.07-4.00)$ & $4.30(4.00-4.70)$ & $<0.001$ \\
\hline $\begin{array}{l}\text { Behavioral Beliefs (BBs) } x \\
\text { Consequence evaluation }\end{array}$ & $4-100$ & $53.00(46.00 ; 60.75)$ & $66.50(63.00 ; 72.00)$ & $<0.001$ \\
\hline Subjective Norm (SN) & $1-5$ & $4.00(4.00-4.01)$ & $5.00(4.00-5.00)$ & $<0.001$ \\
\hline $\begin{array}{l}\text { Normative Beliefs (NB) } x \\
\text { Motivation to agree }\end{array}$ & $3-75$ & $41.00(32.00 ; 48.00)$ & $48.00(32.00 ; 49.00)$ & 0.028 \\
\hline $\begin{array}{l}\text { Perceived Behavioral } \\
\text { Control (PBC) }\end{array}$ & $1-5$ & $4.00(4.00-4.01)$ & $4.50(4.50-5.00)$ & $<0.001$ \\
\hline $\begin{array}{l}\text { Control Beliefs (CB) x } \\
\text { Control Power) }\end{array}$ & $4-100$ & $56.00(50.25 ; 64.00)$ & $64.00(54.50 ; 68.00)$ & 0.007 \\
\hline Behavioral intent (Int) & $1-5$ & $4.00(4.00-4.50)$ & $5.00(4.50-5.00)$ & $<0.001$ \\
\hline
\end{tabular}


Table 3 - Comparison between Theory of Planned Behavior variables before and after the persuasive communication was presented, João Pessoa, Paraíba, Brazil, 2019

\begin{tabular}{lcccccc}
\hline Variables & At & BB & SN & NB & PBC & CB \\
\hline Before the persuasive & & & & & & \\
communication was & & & & & & \\
presented & & & & & & \\
At & - & & & & & \\
BB & $0.44^{+}$ & - & & & & \\
SN & 0.05 & 0.07 & - & & & \\
NB & 0.01 & $0.31^{+}$ & 0.21 & - & & \\
PBC & 0.15 & $0.34^{+}$ & -0.08 & 0.10 & - & \\
CB & $0.31^{+}$ & $0.49^{+}$ & 0.08 & 0.06 & $0.28^{+}$ & - \\
Int & $0.26^{*}$ & $0.38^{+}$ & $0.27^{*}$ & $0.27^{*}$ & 0.21 & $0.27^{*}$ \\
After the persuasive & & & & & & \\
communication was & & & & & & \\
presented & & & & & & \\
At & - & & & & & \\
BB & $0.33^{+}$ & - & & & & \\
SN & 0.18 & -0.01 & - & & & \\
NB & 0.11 & 0.09 & $0.30^{+}$ & - & & \\
PBC & 0.12 & $0.22^{*}$ & $0.39^{+}$ & $0.27^{\dagger}$ & - & \\
CB & 0.18 & $0.36^{+}$ & 0.09 & 0.11 & 0.18 & - \\
Int & $0.20^{*}$ & $0.24^{*}$ & 0.09 & $0.34^{+}$ & 0.19 & -0.03 \\
\hline
\end{tabular}

Note: ${ }^{*} p<0,05 ;{ }^{\dagger} p<0,01 ; A t-$ Attitude; BB-Behavioral Beliefs; SN - Subjective Norm; NB - Normative Beliefs; $P B C$ - Perceived Behavioral Control; $C B$ - Control Beliefs; Int - Behavioral Intent.

\section{DISCUSSION}

The study showed that participants had a positive behavioral intention, and that the intervention contributed by significantly increasing all scores of the TPB variables related to reducing the intake of salt. For the TPB ${ }^{(9,13,17)}$, he Behavioral Intent is an immediate predictor of behavior. Therefore, projected intentions, supported by beliefs, are expected to revert into concrete actions for behavior to really come into effect.

Regarding the direct measure of attitudes, the score found before intervention was found to be favorable for the reduction of salt intake; after exposure to the persuasive communication, the attitude significantly increased. Simultaneously, it was found that the indirect median increased significantly.

Based on these results, it can be said that participants had stronger attitudes and positive behavioral beliefs with regard to the beneficial implications of reducing salt intake, when they evaluated that this restriction has a positive effect on the maintenance of their health, avoiding the worsening of the symptoms and improving quality of life, based on the observation and on the experience accumulated information from information, previous knowledge about the disease, and the reinforcement of the beneficial effects of reducing salt intake, as indicated in the persuasive communication $^{(13)}$. Therefore, they stated that this behavior brings advantages.

Still concerning the attitude components, positive correlations of positive intensity were found between attitudes and behavioral beliefs in both moments evaluated, indicating the need to project educational programs that positively reinforce attitude components (advantages/disadvantages), critically evaluating their consequences and having, as an objective, the diminution of the overload of pulmonary congestion symptoms, increasing the benefits to health and wellbeing.

A pilot-study, clinical trial based on the TPB that used verbal instructions to promote and monitor a low-salt diet, house visits, and telephone reminders, found a significant improvement in the attitude score after six weeks of monitoring ${ }^{(11)}$. It can be considered that interventions focused on specific factors, related to health behaviors may have better chances of success with regard to the actualization of the adherence sought for and needed for people with HF.

Concerning the normative component, the indirect measure, evaluated by normative beliefs (wife, children, brothers), showed that, before and after the communication, the perceived social pressure from significant people had a positive impact in the reduction of salt intake. The participants understood that their social referents approved the behavior and felt motivated to follow through with it after their opinion was received.

The family context in which they were inserted influenced in the reduction of salt intake. Having the social support of significant people may positively sensitize the adherence to the actions prescribed to follow the diet. Therefore, this study recommends involving the positive referents from the social group of the patient to encourage, stimulate, and favor the incorporation of a healthy diet in their lifestyles. Inserting people who are part of the daily life of the patient in the educational activities about the management of care of people with HF is another strategy that can increase therapeutic adherence, to promote the maintenance of functional capacity and quality of life ${ }^{(20)}$.

In accordance with this statement, an international study, whose objective was examining the family adherence to a lowsodium diet and its effect in the adherence of people with $\mathrm{HF}$, concluded that living with a spouse or another family member improved the adherence of the patient to a low-sodium diet. The authors highlight that patients whose relatives also follow the recommended diet presented a lower excretion of sodium in the urine $(p=0.003)$ and were 1.6 times more likely to adhere to the low-sodium diet $(p=0.035)^{(21)}$. Another investigation showed that receiving family support contributes for reducing the intake of salt in people with $\mathrm{HF}^{(22)}$.

Although the referents mentioned belong to the family of the person, it was found to be pertinent to include others, such as neighbors, friends, and work colleagues, as well as those responsible for preparing the meals, in the strategies of interventions targeted at reeducating eating habits and the choice of low-salt foods. An investigation carried out in Italy found that caregivers of people with HF prepared meals or made eating choices to control the excessive intake of salt and avoid a worsening of the symptoms of the disease ${ }^{(23)}$.

That is way it is important to persuade with regard to how important significant social bonds are and their role in the encouragement to diet restrictions during care focused on people with $\mathrm{HF}^{(11,22)}$. Therefore, the adoption of a low-salt diet may be influenced when significant social referents show positive opinions about the treatment and contribute for the encouragement of the behavior.

Regarding direct and indirect measures of the behavioral control perception, it can be noted that, in both moments evaluated, performing the desired behavior was found to involve easy steps. The findings indicate that few difficulties were perceived for the reduction of salt intake ${ }^{(13)}$. Positive reinforcement through clear and direct information influenced the beliefs of control 
about the easy aspects and the resources available to carry out the behavior, leading them to feel more confident with regard to the capacity of dealing with the potential barriers mentioned, such as the palatability of the foods.

It stands out that the communication encourage the patient to advise the person responsible for the meals to reduce the amount of salt in the diet, seeking to improve the taste of foods through the use of herbs and fresh seasoning; preparing meals separately; not adding salt to pre-made foods; and not letting salt available on the table for use at will during meals. These strategies are indicated in literature as elements that need to be included in the education of people with $\mathrm{HF}^{(24)}$.

It is important to consider that, in developing countries such as Brazil, people are consuming processed foods increasingly often, and these foods use high levels of sodium for conservation. Another aspect that should be highlighted is that, in elders with HF, changes in the perception of taste, caused by changes in the aging process and neuro-hormonal changes, increase the appetite for diets with more salt ${ }^{(25)}$.

Since the Perceived Behavioral Control depends on the presence or absence of challenges to bring a behavior into effect, it becomes adequate for interventions to be tested to improve their abilities of reading labels, choosing foods, and techniques to chose meals, reinforcing the perceived ability to deal with possible obstacles ${ }^{(11,13,24)}$.

The results also indicated that the direct measure of the Behavioral Intent presents a positive tendency to carry out the behavior. After the positive persuasive communication, participants had a maximum score with a significant difference, that is, expressed a high intention of behaving in the desired way. However, it stands out that human behavior can be affected by internal and external influences, and that motivation for decision making approximates the execution of the real behavior, behavior that indicates when the individual is determined to $\operatorname{act}^{(9,13,17)}$. This relates to the need of regular interventions to positively influence health behaviors.

The findings of this study are promising, and, coupled with those from other researches which presented satisfactory results through the use of persuasive communication strategies as a form of intervention to influence predictors of behavioral intention, changes in risk behaviors, and of health-protective behaviors ${ }^{(26-27)}$.

It stands out that the previous study ${ }^{(16)}$ on beliefs clarified the key aspects for the construction of an instrument to measure and structure the persuasive communication with regard to the recommendation of the theoretical model, which guides said formulations based on the consideration of specific content and phenomena. Therefore, previously adapted and validated instruments from different cultures may present methodological biases.

It should also be highlighted that the persuasive communication used in this research is a low-cost method that can be reapplied in mobile devices and on-line environments, reaching a higher number of people whose beliefs are similar to those of the group researched. Furthermore, since the content includes image and sound, it limits the potential of external variables, such as low educational levels ${ }^{(13)}$.

The strategy presented here can be improved by making results available for the design of more robust studies. Therefore, this study suggests further studies to be conducted, to assess the residual effect, in the medium and long term, of the persuasive communication in the behavioral variables, since, after the intervention, it was not possible to evaluate the variance of the predictors of the phenomenon being studied throughout time.

\section{Study limitations}

The self-report of behavioral variables is subject to the risk of the social desirability bias ${ }^{(11)}$. Furthermore, the absence of studies that used audiovisual media for the application of persuasive communication in health is a limiting factor when compared to the results found in this investigation.

The specificity of the problem and the small number of specialized services to attend for it restricted the sample, and results reflect the local reality, requiring caution for any generalization of the findings. Although the design of the study reached its objective, longitudinal multicentric researches in different contexts of a country with alimentary and cultural varieties are recommended, to evaluate the residual effect of the intervention in the long term and corroborate or refute the findings of this article.

\section{Contributions to the fields of Nursing, Health or Public Policy}

For the science of Nursing, these results have theoretical and practical implications. Up to this point, no studies with this approach have been found in the clinical and care settings, be it in the Brazilian or Latin-American settings. This study opens perspectives of production, in the national and international contexts, of light-hard technologies (audiovisual media) as care strategies for the non-pharmacological management of people with HF. Therefore, persuasive communications are expected to be applied as nursing interventions to model negative beliefs and strengthen positive ones, actualizing intentions in protective actions for the self-management of one's health condition and for the improvement of their lives.

\section{CONCLUSIONS}

The persuasive communication, short and produced in an audiovisual format, was found to be a feasible strategy that can increase and positively influence the behavioral intent of people with $\mathrm{HF}$ of reducing the salt intake in their diet. This study reinforces the need of carrying out further studies directed at education strategies, with the participation of significant social referents, such as social support agents, in addition to the need of evaluating abilities and barriers for people with HF to follow a low-salt diet.

\section{ACKNOWLEDGMENT}

This study received financial assistance from the PostGraduation Support Program (Programa de Apoio à Pós-Graduação, PROAP) of the Federal University of Paraíba, process No. 23074.053541/2018-18.

To the study participants, as well as the judges who collaborated with their expertise in the validation processes. 


\section{REFERENCES}

1. Chan A, Kinsman L, Elmer S, Khanam M. An integrative review: adherence barriers to a low-salt diet in culturally diverse heart failure adults. Aust J Adv Nurs [Internet]. 2019 [cited 2020 Jun 5];36(1):38-47. Available from: https://www.ajan.com.au/archive/Vol36/Issue1/4Chan.pdf

2. Heo S, Moser DK, Lennie TA, Payne-Emerson H, Welch JL, Weaver M. Development and testing of the feasibility and acceptability of a tailored dietary intervention in patients with heart failure. J Cardiovasc Nurs. 2015;30(3):213-21. https://doi.org/10.1097/ JCN.0000000000000148

3. Song EK, Moser DK, Kang SM, Lennie TA. Self-reported adherence to a low-sodium diet and health outcomes in patients with heart failure. J Cardiovasc Nurs. 2016;31(6):529-34. https://doi.org/10.1097/JCN.0000000000000287

4. Mahtani KR, Heneghan C, Onakpoya, Tierney S, Aronson JK, Roberts N. Reduced salt intake for heart failure: a systematic review. JAMA Intern Med. 2018;178(12):1693-700. https://doi.org/10.1001/jamainternmed.2018.4673

5. Khan MS, Jones DW, Butler J. Salt, no salt, or less salt for patients with heart failure? Am J Med. 2020;133(1):32-38. https://doi.org/10.1016/j. amjmed.2019.07.034.

6. Spineti PPM. Evaluating sodium restriction in heart failure. Arq Bras Cardiol. 2019;112(2):171-2. https://doi.org/10.5935/abc.20190017

7. Comitê Coordenador da Diretriz de Insuficiência Cardíaca. Diretriz Brasileira de Insuficiência Cardíaca Crônica e Aguda. Arq Bras Cardiol. 2018;111 (3):436-539. https://doi.org/10.5935/abc.20180190

8. Yancy CW, Jessup M, Bozkurt B, Butler J, Casey DE Jr, Drazner MH, et al. 2013 ACCF/AHA guideline for the management of heart failure: a report of the American College of Cardiology Foundation/American Heart Association Task Force on Practice Guidelines. J Am Coll Cardiol. 2013;15;62(16):e147-239. https://doi.org/10.1016/j.jacc.2013.05.019

9. Ajzen I. The theory of planned behavior. Organ Behav Hum Decis Process.1991;50:179-211. https://doi.org/10.1016/0749-5978(91)90020-T

10. Martin LR, Haskard-Zolnierek K, DiMatteo MR. Health behavior change and treatment adherence: evidence-based guidelines for improving healthcare. New York: OUP USA; 2014.

11. Welsh D, Lennie TA, Marcinek R, Biddle MJ, Abshire D, Bentley B, et al. Low-sodium diet self-management intervention in heart failure: pilot study results. Eur J Cardiovasc Nurs. 2013;12(1):87-95. https://doi.org/10.1177/1474515111435604

12. Heo S, McSweeney J, Prewitt TE, Lee JY, Moser DK, Shaw-Devine A, et al. A tailored dietary sodium intervention using technology and psychosocial support: a pilot study. J Cardiovasc Nurs. 2019;34(2):137-40. https://doi.org/10.1097/JCN.0000000000000537

13. Sousa MM. Comunicação persuasiva para motivar a intenção de reduzir o consumo de sal em pessoas com insuficiência cardíaca [Tese]. Universidade Federal da Paraíba, João Pessoa; 2019.

14. Conn VS, Algase DL, Rawl SM, Zerwic JJ, Wyman JF. Publishing pilot intervention work. West J Nurs Res. 2010;32(8):994-1010. https://doi. org/10.1177/0193945910367229

15. Hertzog MA. Considerations in determining sample size for pilot studies. Res Nurs Health. 2008;31(2):180-91. https://doi.org/10.1002/nur.20247

16. Sousa MM, Gouveia BLA, Almeida TFC, Freire MLM, Oliveira SHS. Beliefs of people with salt-related heart failure. Rev Enferm UERJ. 2019;(27):e44197. https://doi.org/10.12957/reuerj.2019.44197

17. Ajzen I. Constructing a theory of planned behavior questionnaire [Internet]. 2019 [cited 2020 Jun 5]. Available from: https://people.umass. edu/aizen/pdf/tpb.measurement.pdf

18. Lang TA, Altman DG, Basic statistical reporting for articles published in biomedical journals: the "Statistical analyses and methods in the published literature" or the SAMPL guidelines. Int J Nurs Stud. 2015;52(1):5-9. https://doi.org/10.1016/j.ijnurstu.2014.09.006

19. Ajzen I, Fishbein M. Understanding attitudes and predicting social behavior. New Jersey: Prentice-Hall; 1980.

20. Khaledi GH, Mostafavi F, Eslami AA, Afza HR, Mostafavi F, Akbar B. Evaluation of the effect of perceived social support on promoting self-care behaviors of heart failure patients referred to the cardiovascular research center of Isfahan. Iran Red Crescent Med J. $2015 ; 17(6):$ :e22525. https://doi.org/10.5812/ircmj.22525v2

21. Chung ML, Lennie TA, Mudd-Martin G, Moser DK. Adherence to the low sodium diet in patients with heart failure is best when family members also follow the diet: a multicenter observational study. J Cardiovasc Nurs. 2015;30(1):44-50. https://doi.org/10.1097/ JCN.0000000000000089

22. Dunbar SB, Clark PC, Stamp KD, Reilly CM, Gary RA, Higgins M, et al. Family partnership and education interventions to reduce dietary sodium by patients with heart failure differ by family functioning. Heart Lung. 2016;45(4):311-8. https://doi.org/10.1016/j.hrtlng.2016.04.001

23. Durante A, Paturzo M, Mottola A, Alvaro R, Vaughan Dickson V, Vellone E. Caregiver contribution to self-care in patients with heart failure: a qualitative descriptive study. J Cardiovasc Nurs. 2019;34(2):e28-E35. https://doi.org/10.1097/JCN.0000000000000560

24. Welsh D, Marcinek R, Abshire D, Lennie T, Biddle M, Bentley B, et al. Theory-based low-sodium diet education for heart failure patients. Home Healthc Nurse. 2010;28(7):432-43. https://doi.org/10.1097/NHH.0b013e3181e324e0

25. Cohen LP, Hummel SL, Maurer MS, López-Pintado S, Wessler JD. Salt taste recognition in a heart failure cohort. J Card Fail.2017;23(7):538544. https://doi.org/10.1016/j.cardfail.2017.05.001 
26. Shafieinia M, Hidarnia A, Kazemnejad A, Rajabi R. Effects of a theory based intervention on physical activity among female employees: a quasi-experimental study. Asian J Sports Med. 2016;7(2):e31534. https://doi.org/10.5812/asjsm.31534

27. Park J, Kim SH, Kim JG. Effects of message framing and health literacy on intention to perform diabetes self-care: a randomized controlled trial. Diabetes Res Clin Pract. 2020;161:108043. https://doi.org/10.1016/j.diabres.2020.108043 